\title{
Nationwide efforts for trauma-informed care implementation and workforce development in healthcare and related fields: a systematic review
}

\author{
Resmiye Oral ${ }^{1 \oplus}$, Carol Coohey ${ }^{2 \oplus}$, Kasra Zarei $^{3 \oplus}$, Aislinn Conrad ${ }^{2 \oplus}$, Anne Nielsen ${ }^{4}$,

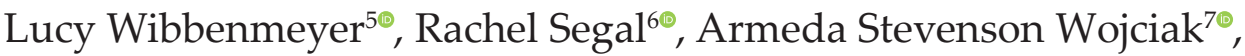 \\ Charles Jennissen $^{8 \oplus}$, Corinne Peek-Asa ${ }^{9 \oplus}$ \\ ${ }^{1}$ Clinical Pediatrics, ${ }^{3}$ Medical Student, ${ }^{5}$ Surgery and ${ }^{6}$ Pediatric Resident and ${ }^{8}$ Pediatrics and Emergency Medicine, Carver College \\ of Medicine, University of Iowa; ${ }^{2}$ School of Social Work, University of Iowa, 'Stead Family Children's Hospital, University of Iowa, \\ ${ }^{7}$ Department of Psychological and Quantitative Foundations, University of Iowa, ${ }^{9}$ College of Public Health, University of Iowa.
}

\begin{abstract}
There is building evidence that Adverse Childhood Experiences without early and proper intervention leads to subsequent short- and long-term behavioral, social, physical and mental health problems. Practitioners, researchers, and healthcare systems have been implementing trauma-informed care (TIC) in a variety of health and human services settings, resulting in improvements in clinical care and prevention of illness by identifying high risk populations. This has led to positive health outcomes including improved compliance, better access to mental health services and reduced health care costs. A systematic review was conducted of studies that focused on TIC implementation in healthcare settings, statewide TIC implementation, impact of adverse childhood experiences on health outcomes, impact of TIC on health outcomes, and evaluation of TIC implementation. A search was conducted in March 2019 to identify studies in PubMed, Medline, and other online literature. We limited our search to articles published in English after 2000. This article aims to review the components of TIC phases of implementation in healthcare settings, success stories across the nation to help the readers understand the importance of a paradigm shift to improve healthcare delivery and health outcomes and to prevent illness starting from childhood with a family centered care perspective.
\end{abstract}

Key words: trauma-informed care implementation and interventions, adverse childhood experiences, childhood trauma, primary-level interventions.

\section{What is Trauma-Informed Care?}

Trauma-informed care (TIC) in healthcare systems is a multilevel, organizational framework to understand and respond to the impact of trauma on both survivors and healthcare providers. Trauma, defined in this context, describes physical and psychological responses to a distressing event or events. Such trauma can be in response to a wide range of stressors, including but not limited to damaging relationships, abuse, neglect, exposure to

Kasra Zarei

kasra-zarei@uiowa.edu

Received 1st October 2019, accepted 4th June 2020. violence, poverty, homelessness, accident, war or natural disasters. These adverse experiences have been linked to health outcomes, and a large body of research has identified that when these events occur during childhood they have lasting and persistent effects on health.

The short- and long-term effects of adverse childhood experiences (ACEs) have been documented by a multitude of studies published over the last decades, as interest in health promotion and disease prevention has grown. ${ }^{1-24}$ Household dysfunction-related ACEs - such as physical, sexual, and emotional abuse, emotional and physical neglect, and mental illness, substance abuse, criminal activity, domestic violence, and parental 
absence-and societal-related ACEs such as community violence, poverty, foster care and discrimination can have negative effects on a child in all health domains: behavioral, physical and physiological, cognitive, social, and mental health. ${ }^{1-26}$ Health-risk behaviors are also associated with an increasing number of ACEs in a dose-response relationship for substance abuse, tobacco use, high-risk sexual behavioral, and overeating. ${ }^{3,5,10,11,13,27}$ A higher number of ACEs has been associated with metabolic risk biomarkers including obesity, high blood pressure, high total cholesterol, low high-density lipoprotein cholesterol levels, and high glycated hemoglobin. ${ }^{17}$

Moreover, individuals exposed to multiple ACEs may lead a "trauma-organized" lifestyle where traumatic events and relationships create a personality, behavior, and lifestyle which may further predispose them to further traumatic situations mental and physical illness throughout life. ${ }^{3,14,24,26,28-30}$ The leading causes of death among adults such as heart disease and stroke, chronic obstructive pulmonary disease, lung cancer, and liver disease are all associated with complex and multiple childhood trauma. ${ }^{7,814}$ Furthermore, individuals, who report a high number of ACEs are more likely to die prematurely, by up to 20 years earlier than individuals who report fewer or no ACEs., ${ }^{3,14,23}$ Individuals who report more ACEs are more likely to report poor or fair health, to have an overall lower sense of well-being, to have poorer access to medical/mental health services, to be less satisfied with their lives, and to have higher work related problems and rates of unemployment. $3,11,22,23,31,32$

Mental health is associated with exposure to multiple ACEs, including learning and behavioral problems, somatic disorders, hallucinations, anxiety and obsessivecompulsive disorders, substance use disorders, depression and subsequent suicide attempts during adulthood as well as posttraumatic stress disorder, which may not always respond to traditional treatment. ${ }^{2,5,10-12,19-21,27,28,33-36}$ Previous studies have explored how ACEs create an environment of traumatic toxic stress that can lead to prolonged activation of the stress response system, excess cortisol circulation, and disruption of the neuroendocrine and immune systems. When the stress response system remains on high alert, it can lead to remodeling of neurological pathways particularly in the hippocampus, amygdala, and prefrontal cortex. ${ }^{1,37-40}$ Lastly, many short- and long-term health problems in association with multiple ACEs increase healthcare utilization and costs in a dose-response curve pattern. ${ }^{22,41}$

Core features of trauma-informed systems include the integration of trauma-informed concepts and principles into policies, procedures, and practices, and building awareness, recognition, and implementation of screening, assessment and treatment services for trauma. ${ }^{42-45}$ Thus, to provide TIC, there must be a commitment to these tasks throughout the organization with a resultant paradigm shift. ${ }^{46,47}$ This shift, then, facilitates the identification of trauma and creates pathways to holistic family well-being assessment and intervention, the prevention of long-term negative health outcomes and a reduction in healthcare costs. . $^{29,42-44,46,48,49}$

TIC can also benefit medical professionals with a personal history of trauma or who have experienced work-related trauma. ${ }^{50,51}$ Trauma-informed organizations that use trauma-sensitive practices can decrease traumarelated triggers and improve staff health, resiliency, and efficiency while enhancing the quality of care for patients and families.52-55 TIC organizations strive to improve multiple practice domains: education of providers to change practice, early identification of children experiencing adversity, treatment through evidence supported and resiliency-focused services, and collaboration within and across agencies that serve children and families in the broader community. ${ }^{34,56-58}$

The Substance Abuse and Mental Health Services Administration (SAMHSA) outlines six broad principles to implement TIC (Table I). ${ }^{59}$ 
Table I. Broad principles of implementation of trauma-informed care.

1. Safety: Conscious organizational effort to promote physical and emotional safety for all members and clients of the organization.

2. Trustworthiness and Transparency: Organization makes decisions with transparency and engenders trust of staff and its clientele.

3. Peer support: Individuals with histories of trauma involved with the organization are engaged to be critical resources for support.

4. Collaboration and mutuality: All members of the organization can equally contribute to the healing of individuals impacted by ACEs.

5. Empowerment, voice and choice: Clients are provided with family- and patient-centered approaches while developing plans of action that empower clients.

6. Cultural, Historical and Gender Issues: Efforts are culturally sensitive and free of prejudices that arise from biases and stereotypes.

These principles include safety, organizational trustworthiness and transparency, peer support, organizational collaboration amongst its members, empowerment of clients, and culturally sensitive care. Understanding how TIC is defined and adopting these principles are typically the first steps for organizations and states interested in implementing traumainformed approaches.

\section{Methodology}

The purpose of this article was to conduct a systematic review of research on how traumainformed care is being implemented in healthcare settings nationally and its effect on the quality of healthcare delivery and on health and other outcomes. We then review efforts by states to implement TIC in multiple systems of care including healthcare, education, juvenile justice, and child welfare settings. Finally, we report on the evidence base for interventions to prevent childhood adversity and trauma before concluding the review with recommendations for future efforts.

A systematic review was conducted of studies that focused on TICimplementationinhealthcare settings, statewide TIC implementation, impact of adverse childhood experiences on health outcomes, impact of TIC on health outcomes, and evaluation of TIC implementation. A search was conducted in March 2019 to identify studies in PubMed, Medline, and other online gray literature. Pubmed and Medline databases were searched using the following keywords: trauma-informed care implementation, adverse childhood experiences and trauma-informed care, trauma prevention, trauma-informed family centered healthcare, statewide traumainformed care implementation.

We limited our search to articles published in English after 2000 that mentioned "traumainformed" or "trauma-informed care" in the abstract, title, or key words. 792 articles and their references were screened if they met any of the following criteria:

- Definition of trauma-informed care, childhood trauma, and adverse childhood experiences

- Discussion of trauma-informed care implementations and interventions, and subsequent changes in practice

- Evaluations of the impact of traumainformed care on child and family health outcomes

- Discussion of primary-level interventions to prevent childhood adversity and trauma

- Discussion of barriers and gaps to implementation of trauma-informed care

One hundred and forty-four articles met the inclusion criteria. The full texts of these articles 
were obtained and classified according to the following categories: 59 articles discussed TIC and ACEs, 38 articles discussed the implementation of TIC in healthcare, 14 articles discussed changes in practice related to TIC, 19 articles discussed the impact of TIC on child and family health outcomes, 29 articles discussed statewide TIC efforts, 8 articles discussed primary prevention of childhood adversity and trauma, and 8 articles discussed barriers and gaps related to implementation of TIC.

\section{Implementation of Trauma-Informed Care in Healthcare}

Many healthcare organizations view TIC as a priority, and numerous studies have reported on the screening of patients for ACEs over the last decade although progress continues to be slow considering the vast healthcare network. ${ }^{60-64}$ Healthcare organizations' commitment to TIC varies substantially and is influenced by different factors at the organizational and individual level.65,66 Organizations and communities that have most successfully implemented TIC have reviewed and amended TIC procedures and policies, provided training to all staff and aligning staff hires with TIC training, followed recommended guidelines, and adopted refinements in TIC, such as service user involvement and ongoing staff training using system-level approaches. ${ }^{67-72}$

Healthcare systems remain an important setting for identifying children and families who have been exposed to trauma. Pediatricians and other childcare providers are integral to the process of implementing TIC, especially if they work in a trauma-informed system and are properly trained..$^{61,63,73-75}$ Within these systems, they ideally have the support and knowledge to recognize, assess and refer traumatized children and their families from inpatient, outpatient, or rehabilitation settings to much needed services within and outside the healthcare system. ${ }^{61,74,76,77}$

Most trauma-informed organizations begin by establishing a stakeholder group to look at the available policies, procedures, and practices to determine how they might better align with a TIC paradigm. ${ }^{53,61,65}$ In some institutions, organizational leadership has implemented institution-wide training and education for their staff and administrators to ensure TIC principles are practiced across the

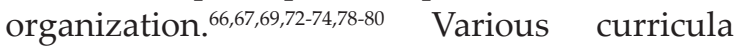
have been developed and piloted for healthcare professionals in different settings, which were designed to ultimately result in more effective patient-centered communication and intervention around ACEs. ${ }^{81-84}$ Existing programs have also discussed self-awareness and self-care in order to mitigate the impact of trauma that healthcare providers may have experienced themselves. ${ }^{85-88}$

In other institutions, front-line providers have created 'grass-roots' training to increase TIC awareness among fellow workers and administrators in their departments, which subsequently led to an institutional paradigm shift. $50,61,67,81,83,89,90$ When the leadership at all levels of an institution identify TIC as a priority, administrators may also change their hiring practices, staff training policies, and their work environments. ${ }^{67}$ Consequently, each organization can create collaborative, safe, and patient-centered environments while proactively preventing secondary traumatic stress. ${ }^{80}$

Universal screening of trauma and resiliency, preferably embedded in routine intake procedures, has been adopted as an important component of TIC in healthcare and other settings, and assumes that most patients have experienced some childhood trauma and all patients possess some resiliency. $5,67,74,78,80-83,89-92$ The assessment of ACEs during routine screening within healthcare settings has resulted in finding more cases in need of trauma-informed interventions. Consequently, some institutions are investigating how they might better integrate behavioral and mental healthcare services with primary care. Researchers stress the importance of the colocalization of behavioral health and primary care providers, supported with an adequate 
number of social workers, to better address the needs of patients with a history of childhood trauma; these practices have led to substantial benefits for patients. ${ }^{61-63,65-67,93-98}$ One prime example of this integrated behavioral health in primary care practice is the Montefiore Hospital Pediatric primary care clinics, which we will review in more detail in a later section. ${ }^{95,96}$ Implementation of TIC has resulted in changes in healthcare practice.

\section{Changes in Practice due to Trauma-Informed Care Implementation}

Although there are numerous efforts to implement TIC in healthcare settings, the literature is sparse on whether it improves the quality of healthcare delivery. The first line of studies report on systems assessment and workforce development. ${ }^{50,99,100}$ These efforts showed that training can result in a paradigm shift toward more TIC practices. ${ }^{76}$ Many practitioners have gone further and reported on how adopting TIC, with its emphasis on patient empowerment and shared decision making, has improved provider-patient communication, which in turn, has led to improved patient satisfaction, medical information recall, compliance and decreased healthcare costs. ${ }^{48,49,101,102}$ In a study that evaluated patients' perception of care delivery before and after primary care physicians completed a six-hour TIC course, providers in the study group were rated higher than providers in the control group on the Partnership Scale. ${ }^{76}$

Implementation of TIC can lead to the holistic care of the patient and their family, addressing their needs through the development of a therapeutic relationship, increased screening and/or by referral to specialists with subsequent improvement in the quality of healthcare delivered. Flynn et al. $^{75}$ reviewed multiple studies on the implementation of TIC in primary healthcare settings and found that most TIC programs quadrupled the proportion of trauma screening (from $12-21 \%$ for different variables to $46-88 \%$ ) and improved physician knowledge, attitudes, and confidence to identify and work with traumatized patients. Briggs et al. ${ }^{60}$ from the Montefiore Hospital Network screened children for trauma using the Healthy Steps model and referred them to behavioral health clinicians embedded in their primary care clinics. The percentage of families referred to services increased from $16 \%$ to $26 \%$, and the percentage of families who complied with treatment increased from $20 \%$ to $63 \%$ with a warm hand-off. ${ }^{60}$

Glowa et al.$^{64}$ reported that in a family practice clinic, by screening for ACEs, practitioners gained new information about their patients. As a result, they discussed the impact of ACEs on their patients' health and the need for intervention almost three times more often with patients with four or more ACEs than with patients with fewer than four ACEs. ${ }^{64}$ Kottenstette and colleagues ${ }^{61}$ assessed children and families for trauma using the Family Wellbeing Assessment model in a child abuse clinic. They reported that recognition of referral for needed services among caregivers increased by close to tenfold (from $5.1 \%$ to $47.0 \%$ ), which more than doubled the rate of referrals, mostly to mental health services. ${ }^{61}$ The same model was implemented in the Emergency Department and the burn unit of the same institution, which increased the recognition of families and patients suffering from multiple trauma, dramatically. ${ }^{62,63}$

\section{Impact of Trauma-Informed Care Interventions on Child and Family Health Outcomes}

Despite the implementation of TIC spreading across healthcare and other family-serving systems, there are few published studies examining its impact on child and family outcomes. Some studies report on how the integration of multiple family serving systems statewide can impact children and families exposed to trauma. One notable multisystem intervention is the Hawaii Department of Health's Project Kealahou, which included the State's mental health, juvenile justice, education, and child welfare systems. ${ }^{103}$ They provided services to girls at risk for truancy and 
incarceration that included case management, peer support, group activities and therapy. The intervention resulted in improvements in the girls' competence, depression symptoms, and behavioral problems and a reduction in caregiver strain. ${ }^{103}$

The Massachusetts Child Trauma Project (MCTP), another multisystem, statewide project, aimed to improve the safety, permanency, and well-being of maltreated children by training child welfare workers and mental health providers on TIC, disseminating information on evidence-based treatment, and integrating the systems of care in their State. Barto et al. ${ }^{104}$ examined provider and family outcomes at pre- and post-intervention. They found that not only the child protection capacity among providers increased, but also recidivism for substantiated maltreatment decreased by $12 \%$ for physical abuse, $14 \%$ for neglect and $15 \%$ for any maltreatment among children. ${ }^{104}$ Bartlett et al. ${ }^{105}$ found that children in the MCTP study had fewer posttraumatic symptoms and behavior problems at six-month followup. Azeem et al. ${ }^{106}$ reported on how traumainformed interventions changed practices in an inpatient child and adolescent psychiatric setting after hospital staff were trained using six core TIC strategies. They reported that episodes of seclusion/restraints in youth decreased from 93 episodes in the pre-intervention to 31 postintervention. ${ }^{106}$

Providing TIC services to women is likely to benefit the wellbeing of children indirectly. For instance, providing interventions involving trauma-informed and trauma sensitive principles for women with mental health issues, substance use disorders, and histories of domestic violence was found to be associated with improved parenting capacity. ${ }^{107,108}$ In a meta-analysis of a nine-site quasi-experimental intervention ( $\mathrm{N}=2,729$ women), mental health and substance use agencies implemented trauma-informed interventions that included case management, integrated treatment for co-occurring disorders, counseling, training on parenting, and consumer involvement including peer support. They reported that post-traumatic symptoms, drug use severity, and mental health symptoms decreased. ${ }^{107,108}$

While the above studies show evidence of TIC implemented in larger systems of care leading to positive health outcomes for children and their caregivers, other studies reported on improvements in health outcomes as a result of TIC implementation directly in healthcare settings. ${ }^{49,103-108}$ Machtinger et al. ${ }^{52}$, for instance, developed a trauma-informed primary care (TIPC) framework for women which showed enhanced healing and healthier environments for themselves, their families including their children and the community. Other studies reported on how Integrated Behavioral Health (IBH) in pediatric clinics proved to be a sustainable and effective method to address and ameliorate pediatric behavior problems, many of which stem from trauma. As a result of this intervention, parents felt more empowered and less stressed-out. ${ }^{60,97,98}$ Additionally, the Montefiore Hospital network's implementation of TIC in pediatric primary care along with $\mathrm{IBH}$, which included social workers, behavioral health clinicians and child and adult psychiatrists, resulted in improved treatment compliance, better health outcomes, increased competence of primary care providers and even reduced healthcare costs. ${ }^{95,96}$ This hospital successfully converted itself into an Accountable Care Organization, the offshoot of The Patient Protection and Affordable Care Act, allowing them to address modifiable social determinants of health, such as individual, family, and societal trauma. ${ }^{77}$

Flynn et al. $^{75}$, conducted a meta-analysis of studies focusing on ACEs and TIC implementation. Their analysis showed that it was difficult to compare study outcomes because they neither explored similar interventions nor used similar outcome measures. As a result, they reported that only half of the studies conducted in primary healthcare settings included patient outcomes. Furthermore, the studies reported mixed results related to child behavior, reported maltreatment, and referral. ${ }^{75}$ However, Marie- 
Mitchell and Kostolanski ${ }^{103}$ in their review of 20 randomized controlled trials, reported that 17 of the studies they reviewed examined parentchild relationship outcomes and 15 examined child health outcomes They also reported that, due to varying ACE assessment tools, screening practices, scopes of intervention and a wide range of outcome measures, the results between studies were difficult to compare. Yet, it is noteworthy that generally, programs had a stronger impact on parent-reported parentchild relationship outcomes, and that medium and high intensity intervention programs were more likely to improve measured health outcomes. ${ }^{109}$

In summary, promising TIC interventions have started to emerge in mental health and pediatric and adult primary healthcare settings. There is a need to conduct multi-center prospective studies to assess and compare trauma-informed intervention modalities and treatments to better assess the impact of TIC on child and family health outcomes.

\section{Statewide Efforts to Build Workforce Capacity and Integrate Systems Serving Families}

Although healthcare settings are practical assessment and intervention entry points for children and families that are struggling with the impact of multi-trauma, the same population may also engage with school, child welfare, and juvenile justice systems. . $9,100,103,105^{\text {States }}$ committed to multisystem TIC approaches demonstrate the importance of working across multiple systems when developing interventions for children and families who are often involved in more than one system. ${ }^{57,67,72}$ This 'trauma-informed systems' approach promotes shared beliefs, values, and practice approaches among organizations, some of which are multilevel interventions that provide workforce training along with policy changes, while others offer targeted services, such as child welfare screenings across multiple agencies. ${ }^{72,105,110,111}$ In fact, with the recognition that cross-system TIC implementation may improve health, social, and educational outcomes simultaneously, numerous states have started efforts to build capacity to deliver TIC across systems serving children and their families, including child welfare, education, health and mental health systems. ${ }^{103,112}$

States have focused their efforts in several areas: assessing whether and to what extent systems are trauma-informed, improving worker capacity through workforce training, disseminating information about traumainformed practice, and integrating systems that serve families and children. ${ }^{103,105}$ The assessment of a program is often an initial step to explore TIC readiness, available tools and gaps, and to develop training programs for workers and interventions for families and children in the child welfare and mental health systems. For instance, California, Oklahoma, and New Hampshire developed a process to evaluate how trauma responsive their child welfare systems were, with the goal of generating recommendations for statewide improvements. Bassuk et al. ${ }^{100}$ developed and validated a brief assessment tool to measure the level of TIC in health and human services to determine training needs, evaluate their practice, and develop trauma-informed policies.

Trauma-informed workforce initiatives within the child welfare system range from trauma education training programs in Louisiana, Tennessee, and Arkansas to multisystem approaches in South Carolina. ${ }^{110,113-115}$ Project Best, a statewide initiative in South Carolina, for example, relied on interprofessional collaboration to impact systems, resulting in improved trauma-informed practices and positive feedback about the community-based learning collaborative component. ${ }^{110}$

In a multifaceted, statewide program spanning child welfare, mental health, and juvenile justice in New Hampshire, the Partners for Change Project implemented case planning for youth who had been screened for trauma, multisystem collaboration, and evidence-based trauma treatments across systems, resulting in improvements in case planning, trauma 
screening, mental health referrals, and overall system performance. ${ }^{116}$ Because the child and family population in child welfare and juvenile justice system is known to have much higher healthcare needs, including physical, mental health and preventive care, implementing TIC in these systems could eventually have a significant impact on health care needs and outcomes of this vulnerable population. ${ }^{79,99,104,117}$

Healthcare and educational systems also interact frequently. It is well known that schools are overwhelmed with behaviorally challenged students, the majority of which receive healthcare; thus, TIC implementation in both systems may enhance health and educational outcomes simultaneously. ${ }^{79,118-121}$ Massachusetts and Washington were among the first two states to provide guidelines for TIC implementation within schools. ${ }^{122}$ Given the growing connection between trauma and the impact on student outcomes, school systems have made major strides in training their workforce. ${ }^{118,119,123} \mathrm{~A}$ strong commitment from school leadership is paramount to successfully implementing training. ${ }^{124,125}$ States have been legislating that schools train their personnel about trauma and ways to mitigate toxic stress (e.g., Nevada, Iowa, Delaware, Wisconsin), using models ranging from intensive two-day training to year-long training. ${ }^{120,126,127}$ Both approaches have increased teachers' ability to respond to trauma, however, the year-long training was more effective. ${ }^{121}$

Wojciak and Smith ${ }^{127}$ conducted a quasiexperimental study evaluating a year long, school wide, trauma-informed intervention with all school staff in an elementary school. Compared to the staff at control schools, staff participating in "WeCan! Building Relationships and Resilience," reported significant increases in their understanding of the impact of trauma on student learning and behavior, their ability to work with students who have experienced trauma, and worker collegiality. In states like Washington and Massachusetts, principals have also reported reductions in office referrals and suspensions when trauma-informed practices were implemented in their schools. ${ }^{128,129}$

\section{Primary Prevention of Childhood Adversity and Trauma}

Programs that focus on population-level primary prevention that can reduce the incidence of ACEs are recognized as having the most potential for long-term impact. Poole et al. conducted a systematic review of programs that included a primary prevention campaign to prevent childhood trauma. ${ }^{130}$ Programs included messages that focused on positive parenting, child development and expectations and asking for help. Although studies generally found positive results, Poole concluded that most studies did not measure changes in the risk factors targeted in the campaign: only one program, Triple-P, had rigorous, controlled evaluations to indicate the positive impact at the individual and population levels. ${ }^{131-134}$ The challenge to the practice community when only one program is evidence-based is the lack of options or implementation strategies for diverse populations and varying levels of funding.

Strategies to reduce ACEs through environmental or policy approaches are promising but largely absent from the published evidence base. Great potential to reduce the burden of ACEs lies with policies that address the social determinants of health inequity, such as programs that reduce poverty, improve housing, or increase access to services such as healthcare and/or education. ${ }^{135-137}$ Thus far, no published studies have examined ACEs as outcomes of these larger policy approaches.

The evidence-base for effective primary prevention strategies to reduce the burden of ACEs, although growing steadily, lags far behind community readiness to implement these strategies. There is critical need to grow the evidence base for programs that impact primary, secondary, or tertiary prevention of ACEs. Investment in program development, implementation, rigorous evaluation, and effective strategies for translation are an important federal research investment. 


\section{Barriers and Gaps Related to Implementation of Trauma-Informed Care}

Despite ongoing efforts to implement TIC practices in healthcare and statewide efforts, there are still several barriers that have prevented wide-scale implementation of TIC. The need for comprehensive training, especially in trauma-sensitive approaches and language to increase provider comfort and competency to implement TIC has long been recognized. Studies investigating screening and identification of trauma victims consistently emphasizes this need, because most providers fear that asking about trauma will offend their clients. ${ }^{138}$ Consequently, even with physical evidence of abuse, $88 \%$ of residents of a domestic violence shelter reported they were not asked about trauma or offered assistance by their dentists. ${ }^{139}$

Provider fear is, in fact, often unfounded because the majority of trauma survivors welcomes questions about their trauma and assistance to address it. ${ }^{138,139}$ The need to be understood by their provider is a repetitive theme in this population. ${ }^{62,140}$ Kottenstette et al. ${ }^{61}$ and Fassel et al. ${ }^{62}$ reported that their twogenerational screening models for childhood trauma, family resiliency, and healthcare needs was well-received by clients; $98 \%$ and $75 \%$ of patients reported this model "could help their providers provide better healthcare" to them.

The same studies that report healthcare provider gaps in confidence and knowledge regarding addressing trauma in their patients also report a keen desire among providers for training in trauma sensitive methods to address clients' psychological distress effectively and confidently. ${ }^{141,142}$ Barriers to asking about trauma may include the providers' discomfort with their own trauma history and the need for self-protection to avoid secondary trauma, compassion fatigue, and burn out. ${ }^{138,139,143,144}$ Because one of the strengths of TIC is its focus on self-care and awareness of a provider's own needs, compassion satisfaction, and peer support, it may mitigate secondary traumatization and contribute to the providers' resilience. ${ }^{59,144}$ Thus, implementation of TIC may enhance provider competencies, offer opportunities to strengthen the provider and patient relationship, and improve the identification of patients that require early and comprehensive interventions.

There is accumulating evidence that communities and systems of care including healthcare are energized to understand TIC, develop their workforce, implement trauma responsive practices, and evaluate outcomes for their clients. Statewide initiatives with strong collaborations among healthcare, mental health, child welfare, juvenile justice, and education systems have great potential to enhance wellbeing, decrease re-victimization, improve health, social, and educational outcomes and promote change at a societal level. ${ }^{26,104}$

To improve care for families and their children, healthcare systems should engage in and lead statewide initiatives to implement TIC across systems, like Hawaii, Massachusetts, Ohio, Wisconsin, Iowa and other states. ${ }^{26,103}$ Through these collaborative efforts, different systems may learn from one another and, in addition, children and families served by these systems are likely to benefit from more synergistic comprehensive and family-centered approaches to care. Healthcare can borrow concepts like capacity building, trauma-informed systems, and assessment from statewide cross-system collaboration.

Healthcare systems moving toward accountable care designation also seems to hold the promise of a healthier population while being costeffective. This life-course approach to disease prevention may offer opportunities at every age to build resilience as recommended by The American Academy of Pediatrics. ${ }^{77}$ Policy makers should prioritize funding for Integrated Behavioral Health to help increase access to care in order to address difficulties early before escalation to improve health outcomes..$^{98}$ 
Given the plasticity of the brain, all patients receiving healthcare have the potential to benefit from family- and patient-centered, traumainformed, resiliency-focused care, which must to be implemented in all components of our healthcare systems. ${ }^{66,67,69,72,79,80,145,146}$ Because the earlier the family-centered interventions are implemented, the higher the potential for better health outcomes, child-serving healthcare systems should work toward this paradigm shift now. ${ }^{67,79,80}$

\section{REFERENCES}

1. Shonkoff JP, Garner AS; Committee on Psychosocial Aspects of Child and Family Health; Committee on Early Childhood, Adoption, and Dependent Care; Section on Developmental and Behavioral Pediatrics. The lifelong effects of early childhood adversity and toxic stress. Pediatrics 2012; 129: e232-e246.

2. Dube SR, Anda RF, Felitti VJ, Chapman DP, Williamson DF, Giles WH. Childhood abuse, household dysfunction, and the risk of attempted suicide throughout the life span: findings from the Adverse Childhood Experiences Study. JAMA 2001; 286: 3089-3096.

3. Felitti VJ, Anda RF, Nordenberg D, et al. Relationship of childhood abuse and household dysfunction to many of the leading causes of death in adults. The Adverse Childhood Experiences (ACE) Study. Am J Prev Med 1998; 14: 245-258.

4. Kessler RC, McLaughlin KA, Green JG, et al. Childhood adversities and adult psychopathology in the WHO World Mental Health Surveys. Br J Psychiatry 2010; 197: 378-385.

5. Burke NJ, Hellman JL, Scott BG, Weems CF, Carrion VG. The impact of adverse childhood experiences on an urban pediatric population. Child Abuse Negl 2011; 35: 408-413.

6. Anda RF, Croft JB, Felitti VJ, et al. Adverse childhood experiences and smoking during adolescence and adulthood. JAMA 1999; 282: 1652-1658.

7. Dong M, Giles WH, Felitti VJ, et al. Insights into causal pathways for ischemic heart disease: adverse childhood experiences study. Circulation 2004; 110: 1761-1766.

8. Anda RF, Brown DW, Dube SR, Bremner JD, Felitti VJ, Giles WH. Adverse childhood experiences and chronic obstructive pulmonary disease in adults. Am J Prev Med 2008; 34: 396-403.
9. Dube SR, Fairweather D, Pearson WS, Felitti VJ, Anda RF, Croft JB. Cumulative childhood stress and autoimmune diseases in adults. Psychosom Med 2009; 71: 243-250.

10. Pilowsky DJ, Keyes KM, Hasin DS. Adverse childhood events and lifetime alcohol dependence. Am J Public Health 2009; 99: 258-263.

11. Mersky JP, Topitzes J, Reynolds AJ. Impacts of adverse childhood experiences on health, mental health, and substance use in early adulthood: a cohort study of an urban, minority sample in the U.S. Child Abuse Negl 2013; 37: 917-925.

12. Schilling EA, Aseltine RH Jr, Gore S. Adverse childhood experiences and mental health in young adults: a longitudinal survey. BMC Public Health 2007; 7: 30 .

13. Hillis SD, Anda RF, Felitti VJ, Nordenberg D, Marchbanks PA. Adverse childhood experiences and sexually transmitted diseases in men and women: a retrospective study. Pediatrics 2000; 106: E11.

14. Brown DW, Anda RF, Tiemeier H, et al. Adverse childhood experiences and the risk of premature mortality. Am J Prev Med 2009; 37: 389-396.

15. Anda R, Tietjen G, Schulman E, Felitti V, Croft J. Adverse childhood experiences and frequent headaches in adults. Headache 2010; 50: 1473-1481.

16. Bader K, Schafer V, Schenkel M, Nissen L, Schwander J. Adverse childhood experiences associated with sleep in primary insomnia. J Sleep Res 2007; 16: 285296.

17. Danese A, Moffitt TE, Harrington H, et al. Adverse childhood experiences and adult risk factors for age-related disease: depression, inflammation, and clustering of metabolic risk markers. Arch Pediatr Adolesc Med 2009; 163: 1135-1143.

18. Duke NN, Pettingell SL, McMorris BJ, Borowsky IW. Adolescent violence perpetration: associations with multiple types of adverse childhood experiences. Pediatrics 2010; 125: e778-e786.

19. Flaherty EG, Thompson R, Litrownik AJ, et al Adverse childhood exposures and reported child health at age 12. Acad Pediatr 2009; 9: 150-156.

20. Maaranen P, Tanskanen A, Haatainen K, KoivumaaHonkanen H, Hintikka J, Viinamaki H. Somatoform dissociation and adverse childhood experiences in the general population. J Nerv Ment Dis 2004; 192: 337-342.

21. Briggs ES, Price IR. The relationship between adverse childhood experience and obsessivecompulsive symptoms and beliefs: the role of anxiety, depression, and experiential avoidance. J Anxiety Disord 2009; 23: 1037-1046. 
22. Chartier MJ, Walker JR, Naimark B. Separate and cumulative effects of adverse childhood experiences in predicting adult health and health care utilization. Child Abuse Negl 2010; 34: 454-464.

23. Mc Elroy S, Hevey D. Relationship between adverse early experiences, stressors, psychosocial resources and wellbeing. Child Abuse Negl 2014; 38: 65-75.

24. Anda RF, Dong M, Brown DW, et al. The relationship of adverse childhood experiences to a history of premature death of family members. BMC Public Health 2009; 9: 106.

25. Garner AS, Shonkoff JP; Committee on Psychosocial Aspects of Child and Family Health; Committee on Early Childhood, Adoption, and Dependent Care; Section on Developmental and Behavioral Pediatrics. Early childhood adversity, toxic stress, and the role of the pediatrician: translating developmental science into lifelong health. Pediatrics 2012; 129: e224-e231.

26. Oral R, Ramirez M, Coohey C, et al. Adverse childhood experiences and trauma informed care: the future of health care. Pediatr Res 2016; 79: 227233.

27. Crouch E, Radcliff E, Strompolis M, Wilson A. Examining the association between adverse childhood experiences and smoking-exacerbated illnesses. Public Health 2018; 157: 62-68.

28. Finkelhor D, Ormrod RK, Turner HA. Polyvictimization: a neglected component in child victimization. Child Abuse Negl 2007; 31: 7-26.

29. Figley CR. In: Figley CR, (ed). Encyclopedia of Trauma: An Interdisciplinary Guide. Thousand Oaks, California: SAGE Publications, 2012.

30. Bloom SL,Farragher B. Destroying sanctuary: The crisis in human service delivery systems. New York, NY: Oxford University Press, 2013.

31. Dube SR, Anda RF, Felitti VJ, Edwards VJ, Croft JB. Adverse childhood experiences and personal alcohol abuse as an adult. Addict Behav 2002; 27: 713-725.

32. Alcala HE, Valdez-Dadia A, von Ehrenstein OS. Adverse childhood experiences and access and utilization of health care. J Public Health (Oxf) 2018; 40: 684-692.

33. Grey HR, Ford K, Bellis MA, Lowey H, Wood S. Associations between childhood deaths and adverse childhood experiences: an audit of data from a child death overview panel. Child Abuse Negl 2019; 90: 22-31.

34. O'Malley DM, Randell KA, Dowd MD. Family adversity and resilience measures in pediatric acute care settings. Public Health Nurs 2016; 33: 3-10.
35. Loudermilk E, Loudermilk K, Obenauer J, Quinn MA. Impact of adverse childhood experiences (ACEs) on adult alcohol consumption behaviors. Child Abuse Negl 2018; 86: 368-374.

36. Chandler GE, Kalmakis KA, Murtha T. Screening adults with substance use disorder for adverse childhood experiences. J Addict Nurs 2018; 29: 172178.

37. Johnson SB, Riley AW, Granger DA, Riis J. The science of early life toxic stress for pediatric practice and advocacy. Pediatrics 2013; 131: 319-327.

38. Elenkov IJ, Chrousos GP. Stress system-organization, physiology and immunoregulation. Neuroimmunomodulation 2006; 13: 257-267.

39. Webster JI, Tonelli L, Sternberg EM. Neuroendocrine regulation of immunity. Annu Rev Immunol 2002; 20: $125-163$.

40. Barch DM, Belden AC, Tillman R, Whalen D, Luby JL. Early childhood adverse experiences, inferior frontal gyrus connectivity, and the trajectory of externalizing psychopathology. J Am Acad Child Adolesc Psychiatry 2018; 57: 183-190.

41. Koball AM, Rasmussen C, Olson-Dorff D, Klevan J, Ramirez L, Domoff SE. The relationship between adverse childhood experiences, healthcare utilization, cost of care and medical comorbidities. Child Abuse Negl 2019; 90: 120-126.

42. Hanson RF, Lang J. A critical look at traumainformed care among agencies and systems serving maltreated youth and their families. Child Maltreat 2016; 21: 95-100.

43. Olivet J, McGraw S, Grandin M, Bassuk E. Staffing challenges and strategies for organizations serving individuals who have experienced chronic homelessness. J Behav Health Serv Res 2010; 37: 226238.

44. Hornor G, Davis C, Sherfield J, Wilkinson K. Traumainformed care: essential elements for pediatric health care. J Pediatr Health Care 2019; 33: 214-221.

45. Center for Substance Abuse Treatment (US). Trauma-Informed Care in Behavioral Health Services. Rockville (MD): Substance Abuse and Mental Health Services Administration (US), 2014: (SMA) 14-4816.

46. Szilagyi M, Kerker BD, Storfer-Isser A, et al. Factors associated with whether pediatricians inquire about parents' adverse childhood experiences. Acad Pediatr 2016; 16: 668-675.

47. DeCandia CJ, Guarino K, Clervil R. TraumaInformed Care and Trauma-Specific Services: A Comprehensive Approach to Trauma Intervention. American Institutes for Research, 2014. 
48. Katz ML, James AS, Pignone MP, et al. Colorectal cancer screening among African American church members: a qualitative and quantitative study of patient-provider communication. BMC Public Health 2004; 4: 62.

49. Sans-Corrales M, Pujol-Ribera E, Gene-Badia J, Pasarin-Rua MI, Iglesias-Perez B, Casajuana-Brunet J. Family medicine attributes related to satisfaction, health and costs. Fam Pract 2006; 23: 308-316.

50. Tink W, Tink JC, Turin TC, Kelly M. Adverse childhood experiences: survey of resident practice, knowledge, and attitude. Fam Med 2017; 49: 7-13.

51. Shi L, Wang L, Jia X, et al. Prevalence and correlates of symptoms of post-traumatic stress disorder among Chinese healthcare workers exposed to physical violence: a cross-sectional study. BMJ Open 2017; 7: e016810.

52. Machtinger EL, Cuca YP, Khanna N, Rose CD, Kimberg LS. From treatment to healing: the promise of trauma-informed primary care. Womens Health Issues 2015; 25: 193-197.

53. Marsac ML, Kassam-Adams N, Hildenbrand AK, et al. Implementing a trauma-informed approach in pediatric health care networks. JAMA Pediatr 2016; 170: 70-77.

54. Moss KM, Ziviani J, Newcombe P, et al. Pathways to increasing the use of psychosocial care with hospitalized children. Psychol Serv 2019; 16: 29-37.

55. Moss KM, Healy KL, Ziviani J, et al. Traumainformed care in practice: observed use of psychosocial care practices with children and families in a large pediatric hospital. Psychol Serv 2019; 16: 16-28.

56. Sege RD, Harper Browne C. Responding to ACEs with HOPE: health outcomes from positive experiences. Acad Pediatr 2017; 17: S79-S85.

57. Hanson RF, Lang J. Special focus section: a critical look at trauma informed care (TIC) among agencies and systems serving maltreated youth and their families. Child Maltreat 2014; 19: 275.

58. Developing a Trauma-Informed Child Welfare System. Child Welfare Information Gateway. Washington, DC: U.S. Department of Health and Human Services, Children's Bureau, 2015 (Accessed March 15, 2019).

59. Wilson C. Pence DM, Conradi L. Trauma-Informed Care. Encyclopedia of Social Work, 2013.

60. Briggs RD, Miguelina G, Schrag-Hershberg R, Cirilli C, Crawford DE, Racine AD. Integrated pediatric behavioral health: implications for training and intervention models. Prof Psychol: Res Pr 2016; 47: 312-319.
61. Kottenstette S, Segal R, Roeder V, et al. Twogenerational trauma-informed assessment improves documentation and service referral frequency in a child protection program. Child Abuse Negl 2020; 101: 104327.

62. Fassel M, Grieve B, Hosseini S, et al. The impact of adverse childhood experiences on burn outcomes in adult burn patients. J Burn Care Res 2019; 40: 294301.

63. Jennissen CA, Long C, Denning G, Oral R. Referral for Follow-up Assessment of High Risk Families Presenting to the ED: A Comparison of Two Methods. American Academy of Pediatrics. Pediatrics 2019; 144: 9.

64. Glowa PT, Olson AL, Johnson DJ. Screening for adverse childhood experiences in a family medicine setting: a feasibility study. J Am Board Fam Med 2016; 29: 303-307.

65. Damian AGallo J, Leaf P, Mendelson T. Organizational and provider level factors in implementation of trauma-informed care after a city-wide training: an explanatory mixed methods assessment. BMC Health Serv Res 2017; 17: 750.

66. Kataoka SH, Vona P, Acuna A, et al. Applying a trauma informed school systems approach: examples from school community-academic partnerships. Ethn Dis 2018; 6: 417-426.

67. Harris M, Fallot RD. Envisioning a trauma-informed service system: a vital paradigm shift. New Dir Ment Health Serv 2001:3-22.

68. Sundborg SA. Knowledge, principal support, selfefficacy, and beliefs predict commitment to traumainformed care. Psychol Trauma 2019; 11: 224-231.

69. Unick GJ, Bassuk EL, Richard MK, Paquette K. Organizational trauma-informed care: associations with individual and agency factors. Psychol Serv 2019; 16: 134-142.

70. Moloney B, Cameron I, Baker A, et al. Implementing a trauma-informed model of care in a community acute mental health team. Issues Ment Health Nurs 2018; 39: 547-553.

71. Baker CN, Brown SM, Wilcox P, Verlenden JM, Black CL, Grant BE. The implementation and effect of trauma-informed care within residential youth services in rural Canada: a mixed methods case study. Psychol Trauma 2018; 10: 666-674.

72. Loomis B, Epstein K, Dauria EF, Dolce L. Implementing a trauma-informed public health system in San Francisco, California. Health Educ Behav 2019; 46: 251-259. 
73. Levy-Carrick NC, Lewis-O'Connor A, Rittenberg E, Manosalvas K, Stoklosa HM, Silbersweig DA. Promoting health equity through trauma-informed care: critical role for physicians in policy and program development. Fam Community Health 2019; 42: 104-108.

74. Purewal Boparai SK, Au V, Koita K. et al. Ameliorating the biological impacts of childhood adversity: a review of intervention programs. Child Abuse Negl 2018; 81: 82-105.

75. Flynn AB, Fothergill KE, Wilcox HC, et al. Primary care interventions to prevent or treat traumatic stress in childhood: a systematic review. Acad Pediatr 2015; 15: 480-492.

76. Green BL, Saunders PA, Power E, et al. Traumainformed medical care: patient response to a primary care provider communication training. J Loss Trauma 2016; 21: 147-159.

77. O'Malley DM. The affordable care act, science, and childhood adversity: a call for pediatric nurses and physicians to lead. Nurs Adm Q 2013; 37: 216-221.

78. Key Ingredients for Successful Trauma-Informed Care Implementation, 2016. (Accessed March 15, 2019).

79. Ko SJ, Ford JD, Kassam-Adams, N. et al. Creating trauma-informed systems: child welfare, education, first responders, health care, juvenile justice. Prof Psychol: ResPr 2008; 39: 396-404.

80. Lucio R, Nelson TL. Effective practices in the treatment of trauma in children and adolescents: from guidelines to organizational practices. J Evid Inf Soc Work 2016; 13: 469-478.

81. Schiff DM, Zuckerman B, Hutton E, Genatossio C, Michelson C, Bair-Merritt M. Development and pilot implementation of a trauma-informed care curriculum for pediatric residents. Acad Pediatr 2017; 17: 794-796.

82. Weiss D, Kassam-Adams N, Murray C, et al. Application of a framework to implement traumainformed care throughout a pediatric health care network. J Contin Educ Health Prof 2017; 37: 55-60.

83. Strait J, Bolman T. Consideration of personal adverse childhood experiences during implementation of trauma-informed care curriculum in graduate health programs. Perm J 2017; 21: 16-061.

84. Stenman K, Christofferson J, Alderfer MA, et al. Integrating play in trauma-informed care: multidisciplinary pediatric healthcare provider perspectives. Psychol Serv 2019; 16: 7-15.

85. Green BL, Saunders PA, Power E, et al. Traumainformed medical care: CME communication training for primary care providers. Fam Med 2015; 47: 7-14.
86. Saakvitne KW, Gamble S, Pearlman LA, Lev BT. Risking connection: a training curriculum for working with survivors of childhood abuse. Baltimore, MD: The Sidran Press, 2000.

87. Brown SM, BakerCN, Wilcox P. Risking connection trauma training: a pathway toward traumainformed care in child congregate care settings. Psychol Trauma 2012; 4: 507-515.

88. Giller E, Vermilyea E, Steele T. Helping Agencies Embrace Relational Work with Trauma Survivors. J Trauma Pract 2006; 5: 65-82.

89. Kalmakis KA, Shafer MB, Chandler GE, Aponte EV, Roberts SJ. Screening for childhood adversity among adult primary care patients. J Am Assoc Nurse Pract 2018; 30: 193-200.

90. Kalmakis KA, Chandler GE, Roberts SJ, Leung K. Nurse practitioner screening for childhood adversity among adult primary care patients: a mixed-method study. J Am Assoc Nurse Pract 2017; 29: 35-45.

91. Oh DL, Jerman P, Silverio Marques S, et al. Systematic review of pediatric health outcomes associated with childhood adversity. BMC Pediatr 2018; 18: 83.

92. Koita K, Long D, Hessler D, et al. Development and implementation of a pediatric adverse childhood experiences (ACEs) and other determinants of health questionnaire in the pediatric medical home: a pilot study. PLoS One 2018; 13: e0208088.

93. Jennissen CA, Evans E, Oral R, Denning G. Child abuse and neglect experts' determination of when a child being left home alone constitutes child neglect. Inj Epidemiol 2018; 5(Suppl 1): 16.

94. Beidas RS, Adams DR, Kratz HE, et al. Lessons learned while building a trauma-informed public behavioral health system in the City of Philadelphia. Eval Program Plann 2016; 59: 21-32.

95. Briggs R. Expanding Awareness and Screening for ACEs in the Bronx: Montefiore Medical Group. In: Center for Health Care Strategies (CHCS). TraumaInformed Care In Action Profile Series. Online: Montefiore Medical Group, 2018.

96. German M, Rinke ML, Gurney BA, et al. Comparing two models of integrated behavioral health programs in pediatric primary care. Child Adolesc Psychiatr Clin N Am 2017; 26: 815-828.

97. Hansel T, Rohrer G, Osofsky J, Osofsky H, Arthur $\mathrm{E}$, Barker C. Integration of mental and behavioral health in pediatric health care clinics. J Public Health Manag Pract 2017; 23 (Suppl 6 Suppl), Gulf Region Health Outreach Program: S19-S24.

98. Talmi A, Muther EF, Margolis K, Buchholz M, Asherin R, Bunik M. The scope of behavioral health integration in a pediatric primary care setting. J Pediatr Psychol 2016; 41: 1120-1132. 
99. Hendricks A, Conradi L, Wilson C. Creating traumainformed child welfare systems using a community assessment process. Child Welfare 2011; 90: 187-205.

100. Bassuk EL, Latta RE, Sember R, Raja S, Richard $M$. Universal design for underserved populations: person-centered, recovery-oriented and trauma informed. J Health Care Poor Underserved 2017; 28: 896-914.

101. Hall JA, Roter DL, Katz NR. Meta-analysis of correlates of provider behavior in medical encounters. Med Care 1988; 26: 657-675.

102. Schneider J, Kaplan SH, Greenfield S, Li W, Wilson IB. Better physician-patient relationships are associated with higher reported adherence to antiretroviral therapy in patients with HIV infection. J Gen Intern Med 2004; 19: 1096-1103.

103. Suarez E, Jackson DS, Slavin LA, Michels MS, McGeehan KM. Project kealahou: improving Hawai'i's system of care for at-risk girls and young women through gender-responsive, traumainformed care. Hawaii J Med Public Health 2014; 73: 387-392.

104. Barto B, Bartlett JD, Von Ende A, et al. The impact of a statewide trauma-informed child welfare initiative on children's permanency and maltreatment outcomes. Child Abuse Negl 2018; 81: 149-160.

105. Bartlett JD, Barto B, Griffin JL, Fraser JG, Hodgdon $\mathrm{H}$, Bodian R. Trauma-informed care in the Massachusetts child trauma project. Child Maltreat 2016; 21: 101-112.

106. Azeem M, Aujla A, Rammerth M, Binsfeld G, Jones RB. Effectiveness of six core strategies based on trauma informed care in reducing seclusions and restraints at a child and adolescent psychiatric hospital. J Child Adolesc Psychiatr Nurs 2017; 30: 170-174.

107. Morrissey JP, Ellis AR, Gatz M, et al. Outcomes for women with co-occurring disorders and trauma: program and person-level effects. J Subst Abuse Treat 2005; 28: 121-133.

108. Vitriol VG, Ballesteros ST, Florenzano RU, Weil $\mathrm{KP}$, Benadof DF. Evaluation of an outpatient intervention for women with severe depression and a history of childhood trauma. Psychiatr Serv 2009; 60: $936-942$

109. Marie-Mitchell A, Kostolansky R. A systematic review of trials to improve child outcomes associated with adverse childhood experiences. Am J Prev Med 2019; 56: 756-764.

110. Hanson RF, Saunders BE, Ralston E, Moreland AD, Peer SO, Fitzgerald MM. Statewide implementation of child trauma-focused practices using the community-based learning collaborative model. Psychol Serv 2019; 16: 170-181.
111. Lang JM, Campbell K, Shanley P, Crusto CA, Connell CM. Building capacity for trauma-informed care in the child welfare system: initial results of a statewide implementation. Child Maltreat 2016; 21: 113-124.

112. Centers for Disease Control and Prevention (CDC) Adverse childhood experiences reported by adultsfive states, 2009. MMWR Morb Mortal Wkly Rep 2010; 59: 1609-1613.

113. Kramer TL, Singel BA, Conners-Burrow NA, Savary PE, Tempel A. A statewide introduction of trauma-informed care in a child welfare system. Child Youth Serv Rev 2013; 35: 19-24.

114. Kuhn TM, Cyperski MA, Shaffer AM, et al. Installing trauma-informed care through the Tennessee Child Protective Services Academy. Psychol Serv 2019; 16: 143-152.

115. Miron D, Scheeringa MS. A statewide training of community clinicians to treat traumatized youths involved with child welfare. Psychol Serv 2019; 16: 153-161.

116. Jankowski MK, Schifferdecker KE, Butcher RL, Foster-Johnson L, Barnett ER. Effectiveness of a trauma-informed care initiative in a state child welfare system: a randomized study. Child Maltreat 2019; 24: 86-97.

117. Lang JM, Ake G, Barto B, et al. Trauma screening in child welfare: lessons learned from five states. J Child Adolesc Trauma 2017; 10: 405-416.

118. Blodgett CL, Lanigan JD. The association between adverse childhood experience (ACE) and school success in elementary school children. Sch PsycholQ 2018; 33: 137-146.

119. Perfect MM, Turley MR, Carlson JS, Yohanna J, Saint Gilles MP. School-related outcomes of traumatic event exposure and traumatic stress symptoms in students: a systematic review of research from 1990 to 2015. SchoolMent Health 2016; 8: 7-43.

120. Perry DL, Daniels, ML. Implementing traumaInformed practices in the school setting: a pilot study. School Mental Health 2016; 8: 177-188.

121. Phifer LW, Hull R. Helping students heal: Observations of trauma-informed practices in the schools. School Mental Health 2016; 8: 201-205.

122. McInerney MMA. Unlocking the Door to Learning: Trauma-Informed Classrooms \& Transformational Schools. Education Law Center 2015.

123. Porche MV, Fortuna LR, Lin J, Alegria M. Childhood trauma and psychiatric disorders as correlates of school dropout in a national sample of young adults. Child Dev 2011; 82: 982-998. 
124. Cole SF, Eisner A, Gregory M, Ristuccia J. Creating and Advocating for Trauma-Sensitive Schools. Boston: Massachusetts Advocates for Children, 2013. https://traumasensitiveschools.org/wpcontent/uploads/2013/11/HTCL-Vol-2-Creatingand-Advocating-for-TSS.pdf

125. Jones W, Berg J, Osher D. Trauma and Learning Policy Initiative (TLPI): Trauma-Sensitive Schools Descriptive Study. Washington DC: American Institutes for Research, 2018.

126. McIntyre EM, Baker CN, Overstreet S, New Orleans Trauma-Informed Schools Learning Collaborative. Evaluating foundational professional development training for trauma-informed approaches in schools. Psychol Serv 2019; 16: 95-102.

127. Wojciak AS, Powers J, Medberry L. Schoolwide trauma informed professional development: We can! Building relationships and resilience. In: Reardon RM, Leonard J (eds). Alleviating the Educational Impact of Adverse Childhood Experiences: School-University-Community Collaboration. Current Perspectives on School/ University/Community Research. Charlotte, NC: Information Age Publishing, 2020; 5.

128. Lincoln High School in Walla Walla, WA, tries a new approach to school discipline-suspensions drop 85\%. 2012. (Accessed October 1, 2019). (https:/ acestoohigh.com/2012/04/23/lincoln-high-schoolin-walla-walla-wa-tries-new-approach-to-schooldiscipline-expulsions-drop-85/.)

129. Massachusetts, Washington State Lead U.S. Trauma-Sensitive School Movement. 2012. (Accessed October 1, 2019). (https:/acestoohigh. com/2012/05/31/massachusetts-washington-statelead-u-s-trauma-sensitive-school-movement/.)

130. Poole MK, Seal DW, Taylor CA. A review of universal campaigns targeting child physical abuse prevention. Health Educ Res 2014; 29: 388-432.

131. Sanders MR, Markie-Dadds C, Tully LA, Bor W. The triple P-positive parenting program: a comparison of enhanced, standard, and self-directed behavioral family intervention for parents of children with early onset conduct problems. J Consult Clin Psychol 2000; 68: 624-640.

132. Prinz RJ, Sanders MR, Shapiro CJ, Whitaker DJ, Lutzker JR. Population-based prevention of child maltreatment: the U.S. Triple p system population trial. Prev Sci 2009; 10: 1-12.

133. Thomas R, Zimmer-Gembeck MJ. Behavioral outcomes of parent-child interaction therapy and triple P-positive parenting program: a review and meta-analysis. J Abnorm Child Psychol 2007; 35: 475-495.
134. Healey D, Healey M. Randomized controlled trial comparing the effectiveness of structured-play (ENGAGE) and behavior management (TRIPLE P) in reducing problem behaviors in preschoolers. Sci Rep 2019; 9: 3497.

135. Henwood BF, Cabassa LJ, Craig CM, Padgett DK. Permanent supportive housing: addressing homelessness and health disparities? Am J Public Health 2013; 103: (Suppl 2): S188-S192.

136. Alegria M, Perez DJ, Williams S. The role of public policies in reducing mental health status disparities for people of color. Health Aff (Millwood) 2003; 22: 51-64.

137. Sakellariou D, Rotarou ES. The effects of neoliberal policies on access to healthcare for people with disabilities. Int J Equity Health 2017; 16: 199.

138. Rodriguez MA, Bauer HM, McLoughlin E, Grumbach K. Screening and intervention for intimate partner abuse: practices and attitudes of primary care physicians. JAMA 1999; 282: 468-474.

139. Raja S, Hoersch M, Rajagopalan CF, Chang P. Treating patients with traumatic life experiences: providing trauma-informed care. J Am Dent Assoc 2014; 145: 238-245.

140. Muzik M, Ads M, Bonham C, Lisa Rosenblum K, Broderick A, Kirk R. Perspectives on traumainformed care from mothers with a history of childhood maltreatment: a qualitative study. Child Abuse Negl 2013; 37: 1215-1224.

141. Alisic E, Tyler MP, Giummarra MJ, et al. Traumainformed care for children in the ambulance: international survey among pre-hospital providers. Eur J Psychotraumatol 2017; 8: 1273587.

142. Hoysted C, Babl FE, Kassam-Adams N, et al. Perspectives of hospital emergency department staff on trauma-informed care for injured children: an Australian and New Zealand analysis. J Paediatr Child Health 2017; 53: 862-869.

143. Nelms AP, Gutmann ME, Solomon ES, Dewald JP, Campbell PR. What victims of domestic violence need from the dental profession. J Dent Educ 2009; 73: 490-498.

144. Robbins RN, Brown H, Ehlers A, et al. A smartphone app to screen for HIV-related neurocognitive impairment. J Mob Technol Med 2014; 3: 23-26.

145. Voss P, Thomas ME, Cisneros-Franco JM, de Villers-Sidani E. Dynamic brains and the changing rules of neuroplasticity: implications for learning and recovery. Front Psychol 2017; 8: 1657.

146. Shaffer J. Neuroplasticity and clinical practice: building brain power for health. Front Psychol 2016; 7: 1118. 